\title{
"Teaching by humiliation" and mistreatment of medical students in clinical rotations: a pilot study
}

\section{Study question}

Our aim was to generate a contemporary understanding of practices that medical teachers in the hospital setting have referred to as "teaching by humiliation". Our research question was: what are the interpretations and experiences of teaching by humiliation among students from two Australian medical schools during their paediatric and adult clinical rotations?

\section{Methods}

We conducted this pilot study using a voluntary, anonymous, self-report survey with a convenience sample of final-stage medical students from the University of Sydney and University of Melbourne at the end of their paediatric rotation in Semester 2 of 2013. The survey consisted of 19 questions: 17 binary yes/no questions, one question with provision for free text, and one open-response question. Teaching by humiliation was undefined and left to the students to interpret. Quantitative data were analysed for frequencies and proportions of binary item responses within and between groups. We used the McNemar test to compare agreement between responses for adult and paediatric rotations. We used a grounded theory approach to analyse qualitative data. The main outcome measures were student reports of experiencing or witnessing teaching by humiliation.

\section{Findings}

Of 151 students invited to participate, 146 (96.7\%) completed the survey. Most reported having experienced $(108 ; 74.0 \%)$ or witnessed $(122 ; 83.6 \%)$ teaching by humiliation during their adult clinical rotations; smaller proportions had experienced $(42 ; 28.8 \%)$ or witnessed $(64 ; 45.1 \%)$ it during their paediatric rotation. There was strong evidence of a difference in responses between the adult and paediatric rotations for experiencing and witnessing teaching by humiliation $(P<0.001$ for each).

The most prevalent behaviours reported were intimidating questioning styles and subtle behaviours, including teachers being nasty, rude or hostile, or belittling or humiliating students. Overt behaviours, including teachers yelling, cursing or swearing at students, were less common. About $30 \%-50 \%$ of students who had experienced or witnessed teaching by humiliation considered it useful for learning.

Students' responses to these practices ranged from disgust and regret about entering the medical profession to endorsement of teachers' public exposure of a student's poor knowledge. Reported victims and perpetrators included junior medical staff, who were subjected to the practices as much as students and were equally likely to be the perpetrators, alongside senior medical and nursing staff.

\section{Limitations}

The generalisability of the findings from this pilot study may be limited due to the use of an unvalidated survey, influence of the recency effect on recall of paediatric compared with adult rotations, our decision to leave open the definition of teaching by humiliation, and inclusion of only two metropolitan medical schools. A larger study may determine the effect size. Responses about witnessing teaching by humiliation may be subjective.

\section{What this study adds to current knowledge}

This study was conducted amid concerns about a culture of harassment and mistreatment in medical schools, medical teachers' continued use of the term "teaching by humiliation" and students' reports of negative experiences. It found that, decades after first being reported and despite the belief of some that students invent or overstate the problem, teaching by humiliation and mistreatment of medical students persist, often in more subtle forms than in the past. Mistreatment was more often reported in adult rotations, but the prevalence in paediatric rotations was still high.

The students in our study considered teaching by humiliation to be part of the culture in medicine: senior and junior doctors do what was done to them as students, and the culture of "toughening up" the young is perpetuated.

Our findings raise four concerns: the effect on a student's learning and mental health, the dissonance with and subsequent undermining of the formal professionalism curriculum, characteristics of the medical profession, and the future medical teaching workforce. We note, too, the potential for negative effects on patients and families who witness abusive behaviour.

As a cultural matter, mistreatment of students requires multilevel and longterm action, especially if commitment of resources to the professionalism curricula is to be productive. The profession and the discipline of medical education would benefit from research to understand the complexity of factors that allow the cultural practices to be perpetuated and to identify ways to shift the culture.

\section{Implications for practice}

Teachers deserve meaningful, ongoing support and professional development in teaching approaches that do not rely on mistreatment, and students deserve support to be assertive and resilient. As a deeply ingrained cultural, institutionalised practice, mistreatment requires focused action to replace the existing culture with one of compassion, tolerance and respect.

Competing interests: No relevant disclosures.

(c) 2015 AMPCo Pty Ltd. Produced with Elsevier B.V. All rights reserved. 


\section{"Teaching by humiliation" and mistreatment of medical students in clinical rotations: a pilot study}

$\mathrm{T}$ he development of professionalism is currently a topic of interest in medical education research and often an explicit goal in medical curricula. Yet for over 25 years, research into the teaching of students and junior doctors has reported the presence of humiliation, intimidation, harassment and abuse, which undermine the teaching of professionalism. $^{2}$ Early research identified forms of abuse ranging from subtle acts, such as derogatory remarks and undermining students' abilities and motivation, to more overt behaviour, including verbal attacks, yelling and nasty or rude behaviour. ${ }^{3,4}$ Subsequent research reported that students were publicly belittled, humiliated or threatened with physical harm, ${ }^{2}$ had their reputation or career threatened; or experienced unjustified criticism, sarcasm and teasing. ${ }^{5}$ Some medical staff reportedly withheld necessary information, ignored students and set impossible deadlines. ${ }^{5}$

More recent research has identified practices including teaching by humiliation, ${ }^{6}$ contempt, belittlement, ${ }^{7}$ harassment, discrimination, assault, ${ }^{8}$ mocking and scorn, ${ }^{9}$ as well as offensive, intimidating, bullying ${ }^{10}$ and demeaning behaviour. ${ }^{11}$ Other subtle forms of abuse identified include refusal to answer questions, return calls or answer pagers, and use of condescending language. ${ }^{12}$ Reports have also described a misuse of the Socratic form of teaching, known as "pimping", 12 in which teachers ask questions aggressively, putting students on the spot and shaming them. ${ }^{6}$

To identify the extent of this problem, the annual North American survey of medical graduates has since 1991 included questions about mistreatment. ${ }^{13}$ There has been little research into the subject in Australia, although a South Australian study identified mistreatment of junior doctors by surgeons and emergency department staff. ${ }^{14}$

\section{Abstract}

Objective: To generate a contemporary understanding of "teaching by humiliation" as experienced by medical students in Australia.

Design, setting and participants: In this pilot study, we surveyed finalstage medical students from two Australian medical schools about their experiences of teaching by humiliation during their adult and paediatric clinical rotations. The students were invited to complete the anonymous survey at the end of their paediatric rotation in Semester 2 of 2013. We used descriptive statistics to analyse quantitative data, and a grounded theory approach to analyse qualitative data.

Main outcome measures: Student reports of experiencing or witnessing teaching by humiliation during their adult and paediatric clinical rotations.

Results: Of 151 students invited to participate, 146 (96.7\%) completed the survey. Most students reported experiencing (108; 74.0\%) or witnessing (118; 83.1\%) teaching by humiliation during adult clinical rotations. Smaller but still sizeable proportions had experienced $(42 ; 28.8 \%)$ or witnessed $(64 ; 45.1 \%)$ it during their paediatric clinical rotation. The humiliating and intimidating behaviours students experienced were mostly more subtle than overt and included aggressive and abusive questioning techniques. The students' responses to these practices ranged from disgust and regret about entering the medical profession to endorsement of teachers' public exposure of a student's poor knowledge.

Conclusions: Practices associated with humiliating medical students persist in contemporary medical education. These practices need to be eradicated, given the evidence that they affect students' learning and mental health and are dissonant with formal professionalism curricula. Interventions are needed to interrupt the transgenerational legacy and culture in which teaching by humiliation is perpetuated.

In our previous study of medical students' expectations and experiences of paediatric rotations, students reported mistreatment. ${ }^{15}$ Our aim in this study was to generate a contemporary understanding of practices that medical teachers in the hospital setting have referred to as "teaching by humiliation". ${ }^{16}$ Our research question was: what are the interpretations and experiences of teaching by humiliation among students from two Australian medical schools during their paediatric and adult clinical rotations?

\section{Methods}

We conducted this pilot study with medical students in the final, clinical-based stage of their degree at two Australian medical schools: at the end of Year 3 at the University of
Sydney, and Year 4 at the University of Melbourne. We used convenience sampling, in which students were invited to voluntarily complete an anonymous survey at the end of their paediatric rotation in Semester 2 of 2013.

The research was approved by the University of Melbourne's Human Research Ethics Committee (HREC protocol 1340653) and endorsed by the University of Sydney's Human Research Ethics Committee.

\section{Survey}

The survey items were developed from factors studied in earlier research. ${ }^{2-5,17}$ The survey consisted of 19 questions: 17 binary yes/no questions, one question with provision for free text, and one open-response question. The first four items asked about teaching by humiliation, and 
1 Analysis of medical students' survey data about teaching by humiliation $(n=146)$

\begin{tabular}{|c|c|c|c|}
\hline Survey item & Paediatric rotation* & Adult rotations* & $P$ \\
\hline 1. Experience of teaching by humiliation & $28.8 \%(42 / 146)$ & $74.0 \%(108 / 146)$ & $<0.001$ \\
\hline $\begin{array}{l}\text { 3. Witnessed other students being taught by } \\
\text { humiliation }\end{array}$ & $45.1 \%(64 / 142)$ & $83.6 \%(122 / 146)$ & $<0.001$ \\
\hline $\begin{array}{l}\text { 5. Experience of being yelled or shouted at by medical } \\
\text { or surgical teaching staff }\end{array}$ & $1.4 \%(2 / 146)$ & $13.7 \%(20 / 146)$ & $<0.001$ \\
\hline $\begin{array}{l}\text { 6. Witnessed medical or surgical teaching staff yelling } \\
\text { or shouting at other students }\end{array}$ & $4.8 \%(7 / 146)$ & $30.1 \%(44 / 146)$ & $<0.001$ \\
\hline $\begin{array}{l}\text { 7. Experience of medical or surgical teaching staff } \\
\text { being nasty, rude or hostile }\end{array}$ & $31.0 \%(45 / 145)$ & $55.9 \%(81 / 145)$ & $<0.001$ \\
\hline $\begin{array}{l}\text { 8. Witnessed medical or surgical teaching staff being } \\
\text { nasty, rude or hostile to other students }\end{array}$ & $29.2 \%(42 / 144)$ & $58.2 \%(85 / 146)$ & $<0.001$ \\
\hline $\begin{array}{l}\text { 9. Experience of being belittled or humiliated by } \\
\text { medical or surgical teaching staff }\end{array}$ & $19.2 \%(28 / 146)$ & $40.7 \%(59 / 145)$ & $<0.001$ \\
\hline $\begin{array}{l}\text { 10. Witnessed medical or surgical teaching staff } \\
\text { belittling or humiliating other students }\end{array}$ & $22.9 \%(33 / 144)$ & $56.9 \%(82 / 144)$ & $<0.001$ \\
\hline $\begin{array}{l}\text { 11. Experience of being cursed or sworn at by medical } \\
\text { or surgical teaching staff }\end{array}$ & $3.4 \%(5 / 146)$ & $4.8 \%(7 / 146)$ & 0.48 \\
\hline $\begin{array}{l}\text { 12. Witnessed medical or surgical teaching staff curse } \\
\text { or swear at other students }\end{array}$ & $2.8 \%(4 / 145)$ & $10.3 \%(15 / 145)$ & 0.002 \\
\hline $\begin{array}{l}\text { 13. Experience of medical or surgical teaching staff } \\
\text { asking questions in intimidating way }\end{array}$ & $43.4 \%(63 / 145)$ & $71.2 \%(104 / 146)$ & $<0.001$ \\
\hline $\begin{array}{l}\text { 15. Witnessed medical or surgical teaching staff ask } \\
\text { questions in intimidating way to other students }\end{array}$ & $54.1 \%(79 / 146)$ & $80.0 \%(116 / 145)$ & $<0.001$ \\
\hline $\begin{array}{l}\text { 17. Witnessed or heard other hospital staff being rude } \\
\text { to students }\end{array}$ & $34.5 \%(50 / 145)$ & $60.4 \%(87 / 144)$ & $<0.001$ \\
\hline
\end{tabular}

* Data missing for some participants.

subsequent items asked about specific practices or behaviours associated with it. Teaching by humiliation was deliberately undefined and left to the students to interpret; the students were given the opportunity to define and comment on the term in the open-response question. We conducted a paper-based survey because students in the previous cohort had recommended it over an online survey to obtain a higher participation rate.

\section{Statistical analysis}

Data were analysed in SAS version 9.3 (SAS Institute) to describe frequencies and proportions of binary item responses within and between groups. We used the McNemar test to compare agreement between responses for adult rotations (in medicine, surgery, general practice, etc) and the paediatric rotation. No adjustment was made for multiple statistical comparisons.
We analysed students' free-text responses using a grounded theory approach. ${ }^{18}$ The initial analysis was conducted separately by two of us (J $\mathrm{B}$ and $\mathrm{KS}$ ) using the constant comparison process to identify themes in the data. We then compared these analyses and modified the themes through discussion and agreement. One of the initial analysts (J B) then grouped the themes into categories, which the other (K S) reviewed and endorsed as valid.

\section{Results}

Of the 151 students invited to participate in the study, 146 (96.7\%) completed the survey (68/73 in Sydney and 78/78 in Melbourne). Most participants reported having experienced $(74.0 \%)$ or witnessed $(83.6 \%)$ teaching by humiliation during their adult clinical rotations; smaller proportions had experienced $(28.8 \%)$ or witnessed (45.1\%) it during their paediatric clinical rotation (Box 1). There was strong evidence of a difference in responses between the adult and paediatric rotations for experiencing and witnessing teaching by humiliation $(P<0.001$ for each).

When asked about specific behaviours students associated with teaching by humiliation, experiencing $(71.2 \%)$ or witnessing $(80.0 \%)$ intimidating questioning styles were the most prevalent during adult rotations. Smaller but still sizeable proportions of students referred to experiencing $(43.4 \%)$ or witnessing (54.1\%) intimidating questioning styles during their paediatric rotation (Box 1). There was strong evidence of a difference in responses between the adult and paediatric rotations for these $(P<0.001$ for each).

Larger proportions of students had experienced or witnessed subtle rather than overt forms of teaching by humiliation. Subtle forms included teachers being nasty, rude or hostile, or belittling or humiliating students. There was strong evidence 
of differences between adult and paediatric rotations for experiencing and witnessing these behaviours ( $P$ $<0.001$ for each) (Box 1).

The more overt behaviours associated with teaching by humiliation included teachers yelling, shouting, cursing or swearing at students. There were more reports of experiencing and witnessing these behaviours in adult than paediatric rotations, with moderate to strong statistical evidence for differences in all behaviours except experiencing cursing or swearing, which was infrequent $(<5 \%)$ in all rotations (Box 1).

Box 2 shows the proportions of students who had experienced and witnessed teaching by humiliation and an intimidating questioning style and considered them useful for learning. About $30 \%-50 \%$ of these students considered the mistreatment to be useful for learning.

Many students had seen or heard hospital staff other than medical or surgical teachers being rude to medical students (34.5\% in paediatric rotations; $60.4 \%$ in adult rotations). The specific professional group most frequently named was nursing and midwifery, reported by $59.0 \%$ (46/78) of University of Melbourne students and $35.3 \%(24 / 68)$ of University of Sydney students. Administrative staff were also named. One student noted that the behaviours were "ubiquitous" and another said that "almost all [professional groups] on different occasions" exhibited these behaviours.
Analysis of students' comments on the open-response question identified five main themes (Box 3 ):

- Students responded differently to practices encompassed by teaching by humiliation, ranging from disgust to excusing or defending teachers' practices that exposed a student's poor knowledge.

- Teaching by humiliation was understood to persist because it is a traditional practice in the culture of medicine and medical education, and an accepted way of enculturating the young, helping them to "toughen up" for medical practice.

- Students noticed the aggressive ways in which medical teachers ask questions, sometimes explaining it as reflecting a lack of teaching expertise.

- The reported victims and perpetrators of teaching by humiliation included junior medical staff, who were subjected to the practices as much as students; they were equally likely to be the perpetrators, alongside senior medical and nursing staff.

- The intimidating and humiliating practices were experienced and witnessed more in some settings than others: urban rather than rural hospitals; adult more than paediatric rotations; and in surgery and emergency departments.

\section{Discussion}

Our study found that many students in two large Australian medical schools had experienced or witnessed teaching by humiliation during their paediatric and adult clinical rotations. Decades after first being reported and despite the belief of some that students invent or overstate the problem, teaching by humiliation and mistreatment of students persist, often in more subtle forms than those reported in the past.

Providing the survey in paper form enabled ease of completion, resulting in a high response rate. However, the generalisability of the findings from this pilot study may be limited due to the use of an unvalidated survey, influence of the recency effect on recall of paediatric compared with adult clinical rotations, our decision to leave open the definition of teaching by humiliation, and inclusion of only two metropolitan medical schools. A larger study may determine the effect size. Further, responses about witnessing teaching by humiliation may have been subjective, given that a student is projecting his or her own views into a scenario. However, for this exploratory study, we wanted to gauge the extent of these practices, whether experienced or witnessed. Despite these limitations, our findings suggest a contemporary understanding of teaching by humiliation in Australian medical education.

Our research was conducted amid concern in medical education about a culture of harassment and mistreatment in medical schools, ${ }^{1,13}$ medical teachers' continued use of the term

2 Mistreatment considered useful for learning by medical students

\begin{tabular}{|c|c|c|}
\hline Survey item & Paediatric rotation* & Adult rotations* \\
\hline $\begin{array}{l}\text { 2. Experienced teaching by humiliation and considered it } \\
\text { useful for learning }\end{array}$ & $50.0 \%(21 / 42)$ & $40.7 \%(44 / 108)$ \\
\hline $\begin{array}{l}\text { 4. Witnessed teaching by humiliation and considered it } \\
\text { useful for learning }\end{array}$ & $42.2 \%(27 / 64)$ & $32.0 \%(39 / 122)$ \\
\hline $\begin{array}{l}\text { 14. Experienced intimidating questioning and considered } \\
\text { it useful for learning }\end{array}$ & $42.9 \%(27 / 63)$ & $40.4 \%(42 / 104)$ \\
\hline $\begin{array}{l}\text { 16. Witnessed intimidating questioning and considered it } \\
\text { useful for learning }\end{array}$ & $40.5 \%(32 / 79)$ & $35.3 \%(41 / 116)$ \\
\hline
\end{tabular}

* Denominators represent number of students who reported experiencing or witnessing each instance of teaching by humiliation. 
3 Themes identified in medical students' comments on the open-response question, with illustrative quotations

Theme

A spectrum of experiences, interpretations and explanations: devastating but acceptable

Medical culture: necessary toughening up, transgenerational legacy; other effects: attendance, career choices

Teaching skills, questioning skills: the cause, the problem and a potential solution

Groups and contexts: victims and perpetrators, specialties, seniority

Different settings

\section{Example quotations}

"Teaching by humiliation is despicable and does not help anyone."

"It is 'humiliating' to be put on the spot and have your knowledge and understanding tested publicly, but I find it to be a fantastic way to learn and consolidate. Rudeness and insults, however, should have no place in this method."

"I get the feeling it is culturally ingrained and perpetuated."

"I understand they think it's good for character and learning but it just demoralises you and makes you feel defeated and disheartened and not want to show up."

"The culture of bastardisation in the medical profession has to stop. Had I known it was like this, I never would have given up a good job that I loved to do medicine."

"You learn a lot from someone who's friendly, engaging and WANTS to teach. I don't mind being asked questions, it's just the manner in which they do it."

"This is still part of the medical culture, though I think it is reducing. I wonder whether it is the case of some do not know how to educate in any other way."

"Common for consultants to expect a large amount of knowledge from you in a specialist area and then say 'you know nothing and are pathetic' when you don't."

"All consultants were excellent but I found some of the other members of the medical team (eg, Fellows, registrars) often neglected or belittled us."

"It is common for surgeons to teach [by] questioning you in front of your peers and humiliating or making fun of you if you get the wrong answer."

"I have recently come back from a rural term, where teaching and staff attitudes were excellent." "teaching by humiliation" 6 and students' reports of negative experiences, such as being "constantly ignored and told to disappear". ${ }^{15}$ A large proportion of the students in our survey reported experiencing and/or witnessing a range of behaviours that they associated with teaching by humiliation. Although the proportion was higher in adult rotations, there was considerable reporting of these practices in paediatric rotations.

Our results confirm the findings of decades of research with medical students, in which up to $95 \%$ reported having experiences of behaviour they associated with teaching by humiliation. ${ }^{2,3,6,7,14,17,19-22}$ Any suspicion that our findings reflect overreporting of teaching by humiliation by medical students is challenged by research that found senior staff underestimated the prevalence of this practice in the training of junior doctors. ${ }^{5}$ More recently, a review of the literature found that less than a third of victims report this type of abuse because of a lack of awareness of reporting procedures, suspicion the report would not be acted upon, and fear of retaliation..$^{21}$ In other research, students said they were advised against reporting. ${ }^{10}$ We assume that the medical students who voluntarily completed our anonymous survey reported accurately.

Our study showed that in the contemporary medical education environment, teaching by humiliation is most often manifested in subtle rather than overt behaviour, consistent with other recent research. ${ }^{12}$ More students reported experiencing or witnessing rudeness and belittling behaviour; fewer experienced or witnessed explicit yelling and swearing. The study also highlights the widespread practice of aggressive questioning as a teaching technique, which shames some students and is regarded as an abuse of the Socratic method. ${ }^{12}$

Up to half of the students in our study who had experienced or witnessed mistreatment considered it to be useful for learning. In research from Canada, junior doctors rationalised their experience of mistreatment, believing it was useful if the content of the teaching was important or if the learner had not understood the content presented in other ways. ${ }^{22}$ In addition, some junior doctors believed public chastisement and intimidating behaviour was just "redirection" and "the natural socialisation of a good doctor". ${ }^{22}$ Future research could seek to understand what is at play in these beliefs.

Our study also highlighted that physicians and surgeons are not the only hospital staff responsible for mistreating students. Nurses, midwives and administrative staff were commonly named as perpetrators. Thus, when thinking about abuse as a cultural matter, our attention must be directed toward the culture of hospitals and all health care professionals, not just medicine or medical education. 
The findings of our study raise four concerns: the effect on the individual student's learning and mental health, the dissonance with and subsequent undermining of the formal professionalism curriculum, characteristics of the medical profession, and the future medical teaching workforce. We note, too, the potential for negative effects on patients and families who witness abusive behaviour.

For optimal learning to occur, the environment should be free of fear and unnecessary anxiety. ${ }^{23}$ Previous research has found teaching by humiliation can affect students' mental health, having an impact on their confidence, loyalty to the institution and care of patients. ${ }^{21} \mathrm{~A}$ study in the United States found that mistreated medical students were more likely to be stressed, depressed and suicidal, to binge drink and to believe their faculty did not care about them. ${ }^{20} \mathrm{~A}$ more recent study found associations with student burnout. ${ }^{19}$

Our findings are at odds with the current explicit teaching of professionalism in medical schools. Whether professionalism is thought of as desirable professional characteristics or a process wherein practitioners become trustworthy, practices that novices experience as humiliating undermine what is taught. ${ }^{2}$ Habitual denial or rationalisation of students' experiences of humiliation as being oversensitivity to negative feedback is unlikely to advance the profession.

The mistreatment of students also affects the profession in other ways. Two students in our study commented that they would not have trained in medicine if they had known about the mistreatment. Other research found that about $30 \%$ of students who had been mistreated had considered dropping out of medicine or would have chosen a different profession if they had known about the extent of mistreatment. ${ }^{7}$ In attempting to explain why medical students are mistreated, the authors of that study explored the "different moral orders" that characterise professions and highlighted the influence of the medical and hospital hierarchy on the institutionalisation of abusive behaviour. ${ }^{7}$ Others point to the hierarchical and competitive medical education culture ${ }^{6}$ and the "dog-eat-dog culture of the medical workplace". ${ }^{10}$ The medical culture accepts disrespectful behaviour towards patients, staff and students that would not be acceptable in other social interactions. ${ }^{12}$ In our study, students considered teaching by humiliation to be part of the culture of medicine: senior and junior doctors do what was done to them as students, and the culture of "toughening up" the young is perpetuated.

It has been suggested that physicians' values and behaviours develop from the attitudes they adopt during university studies. ${ }^{7}$ The risk is that through teaching by humiliation, some medical students will accept their place in the medical hierarchy, ${ }^{24}$ align their values to those of their teachers and adjust their career plans to survive. ${ }^{6,9}$ By doing so, they maintain the dominant, hierarchical culture of medicine $e^{24}$ and sustain a cycle of abuse wherein victims become perpetrators. ${ }^{1,23}$

As in earlier research, some students in our study suggested the solution is to help teachers gain an understanding of safe learning environments and develop approaches to teaching that do not rely on mistreatment. ${ }^{7,22}$ However, we suspect that because the problem is cultural and institutionalised, leaving a "transgenerational legacy", it is unlikely to transform through improved teaching expertise alone. Rather, as a deeply ingrained cultural practice, mistreatment of medical students requires focused action to interrupt the existing culture and replace it with "a culture of compassion, tolerance, and respect". ${ }^{25}$

As a cultural matter, mistreatment of students requires multilevel and longterm action, especially if commitment of resources to the professionalism curricula is to be productive. The profession and the discipline of medical education would benefit from research to understand the complexity of factors that allows the cultural practices to be perpetuated and to identify ways to shift the culture. At the same time, current and future teachers deserve meaningful, ongoing support and professional development, and students deserve support to be assertive and resilient.

Acknowledgements: We thank the medical students for the time they gave in completing the survey.

Competing interests: No relevant disclosures.

(c) 2015 AMPCo Pty Ltd. Produced with Elsevier B.V. All rights reserved. 
1 Neville AJ. In the age of professionalism, student harassment is alive and well. Med Educ 2008; 42 : 447-448.

2 Kassebaum DG, Cutler ER. On the culture of student abuse in medical school. Acad Med 1998; 73: 1149-1158.

3 Sheehan KH, Sheehan DV, White $K$, et al. A pilot study of medical student 'abuse': student perceptions of mistreatment and misconduct in medical school. JAMA 1990; 263: 533537.

4 Silver HK. Medical students and medical school. JAMA 1982; 247: 309310.

5 Daugherty SR, Baldwin DC Jr, Rowley BD. Learning, satisfaction, and mistreatment during medical internship: a national survey of working conditions. JAMA 1998; 279: 1194-1199.

6 Lempp H, Seale C. The hidden curriculum in undergraduate medical education: qualitative study of medical students' perceptions of teaching. BMJ 2004; 329: 770-773.

7 Rautio A, Sunnari V, Nuutinen M, Laitala M. Mistreatment of university students most common during medical studies. BMC Med Educ 2005; 5: 36.

8 D’Eon M, Lear N, Turner M, Jones C. Perils of the hidden curriculum revisited. Med Teach 2007; 29: 295-296.

9 Phillips SP, Clarke M. More than an education: the hidden curriculum, professional attitudes and career choice. Med Educ 2012; 46: 887-893.

10 Rees CE, Monrouxe LV. "A morning since eight of just pure grill": a multischool qualitative study of student abuse. Acad Med 2011; 86: 1374-1382.

11 Leape L, Shore M, Dienstag JL. In reply to Alexander et al [letter]. Acad Med 2013; 88: 741-742.

12 Anderson J. Can "pimping" kill? The potential effect of disrespectful behavior on patient safety. JAAPA 2013; 26: 53-56.

13 Mavis B, Sousa A, Lipscomb W, Rappley MD. Learning about medical student mistreatment from responses to the medical school graduation questionnaire. Acad Med 2014; 89 : 705-711.

$14 \mathrm{Nabi} \mathrm{H,} \mathrm{Harley} \mathrm{S,} \mathrm{Murphy} \mathrm{E.} \mathrm{The} \mathrm{perils}$ and triumphs of night surgical residents across South Australia. J Surg Educ 2013; 70: 265-272.

15 Scott KM, Barrett J, Cheetham V, et al. Mismatch between medical student expectations and experience: student over-entitlement or programs needing reform? Focus on Health Professional Education 2014; 15 (3): 41-52.

16 Barrett JK. Medical teachers in Australian hospitals: knowledge, pedagogy and identity [doctoral thesis]. Melbourne: University of Melbourne, 2013.

17 Silver HK, Glicken AD. Medical student abuse: incidence, severity and significance. JAMA 1990; 263: 527-532.

18 Glaser BG, Strauss AL. The discovery of grounded theory: strategies for qualitative research. London: Weidenfeld and Nicolson, 2010.

19 Cook AF, Arora VM, Rasinski KA, et al. The prevalence of medical student mistreatment and its association with burnout. Acad Med 2014; 89: 749-754.

20 Frank E, Carrera JS, Stratton T, et al. Experiences of belittlement and harassment and their correlates among medical students in the United States: longitudinal survey. BMJ 2006; 333 : 682-684.

21 Dyrbye LN, Thomas MR, Shanafelt TD. Medical student distress: causes, consequences, and proposed solutions. Mayo Clin Proc 2005; 80: 1613-1622.

22 Musselman LJ, MacRae HM, Reznick RK, Lingard LA. 'You learn better under the gun': intimidation and harassment in surgical education. Med Educ 2005; 39 : 926-934.

23 Spencer J, Lennard T. Time for gun control? Med Educ 2005; 39: 868-869.

24 Gaufberg EH, Batalden M, Sands R, Bell SK. The hidden curriculum: what can we learn from third-year medical student narrative reflections? Acad Med 2010; 85: 1709-1716.

25 Krugman RD, Jones MD Jr, Lowenstein SR. Can we learn civility? Reflections on the challenge of changing culture. Acad Med 2014; 89: 1586-1588. 